\title{
The Usefulness of Symptom-based Subtypes of Functional Dyspepsia for Predicting Underlying Pathophysiologic Mechanisms and Choosing Appropriate Therapeutic Agents
}

\author{
Kwang Jae Lee \\ Department of Gastroenterology, Ajou University School of Medicine, Suwon, Gyeonggi-do, Korea
}

\begin{abstract}
Functional dyspepsia (FD) is considered to be a heterogeneous disorder with different pathophysiological mechanisms or pathogenetic factors. In addition to traditional mechanisms, novel concepts regarding pathophysiologic mechanisms of FD have been proposed. Candidates of therapeutic agents based on novel concepts have also been suggested. FD is a symptom complex and currently diagnosed by symptom-based Rome criteria. In the Rome criteria, symptom-based subtypes of FD including postprandial distress syndrome and epigastric pain syndrome are recommended to be used, based on the assumption that each subtype is more homogenous in terms of underlying pathophysiologic mechanisms than FD as a whole. In this review, the usefulness of symptombased subtypes of FD for predicting underlying pathophysiologic mechanisms and choosing appropriate therapeutic agents was evaluated. Although several classic pathophysiologic mechanisms are suggested to be associated with individual dyspeptic symptoms, symptom-based subtypes of FD are not specific for a certain pathogenetic factor or pathophysiologic mechanism, and may be frequently associated with multiple pathophysiologic abnormalities. Novel concepts on the pathophysiology of FD show complex interactions between pathophysiologic mechanisms and pathogenetic factors, and prediction of underlying mechanisms of individual patients simply by the symptom pattern or symptom-based subtypes may not be accurate in a considerable proportion of cases. Therefore, subtyping by the Rome criteria appears to have limited value to guide therapeutic strategy, suggesting that the addition of objective parameters or subclassification reflecting physiologic or pathologic tests may be necessary for the targeted therapeutic approaches, particularly when therapeutic agents targeting novel mechanisms are available.
\end{abstract}

(J Neurogastroenterol Motil 2021;27:326-336)

\section{Key Words}

Dyspepsia; Pathophysiology; Rome; Therapeutics

\section{Introduction}

Functional dyspepsia (FD) is a common disorder in the population worldwide, but its pathophysiologic mechanisms have not been completely elucidated yet. Diverse pathophysiologic mechanisms including novel concepts have been proposed. Classically, the main pathophysiologic mechanisms include hypersensitivity to distending or chemical stimuli, impaired gastric accommodation to a meal and delayed gastric emptying. ${ }^{1-6}$ Although therapeutic

Received: February 18, 2021 Revised: May 1, 2021 Accepted: May 7, 2021

(a) This is an Open Access article distributed under the terms of the Creative Commons Attribution Non-Commercial License (http://creativecommons. org/licenses/by-nc/4.0) which permits unrestricted non-commercial use, distribution, and reproduction in any medium, provided the original work is properly cited.

${ }^{*}$ Correspondence: Kwang Jae Lee, MD, PhD Department of Gastroenterology, Ajou University Hospital, Ajou University School of Medicine, 164 Worldcup-ro, Yeongtong-gu, Suwon, Gyeonggi-do 16499, Korea

Tel: +82-31-2195102, Fax: +82-31-2195999, E-mail: kjl@ajou.ac.kr 
approaches targeting underlying mechanisms are considered to be efficient in the treatment of FD, it is unclear whether symptombased subtypes are useful for predicting underlying mechanisms and choosing appropriate therapeutic agents. A relationship of the several distinct pathophysiological mechanisms with individual dyspeptic symptoms has been suggested, ${ }^{1-5}$ but it is not clearly established. Furthermore, dyspeptic patients commonly complain of multiple dyspeptic symptoms rather than a single symptom, and their symptoms can change over time.

The Rome IV criteria prefer to use the diagnostic names of subtypes such as postprandial stress syndrome (PDS) and epigastric pain syndrome (EPS) rather than FD as a whole. ${ }^{7}$ Such a suggestion is based on the assumption that each subtype is more homogenous in terms of underlying pathophysiologic mechanisms, compared with FD as a whole. Thus, symptom-based subtypes may be useful for choosing appropriate therapeutic agents. Actually, in real clinical practice, proton pump inhibitors (PPIs) or visceral analgesics are recommended to be used as the first treatment of EPS, and the use of prokinetics are recommended first for the treatment of PDS. ${ }^{8-11}$ Besides classic pathophysiologic mechanisms such as delayed gastric emptying, impaired gastric accommodation to a meal, and hypersensitivity to distending or chemical stimuli, novel concepts have recently been proposed. Duodenal abnormalities such as altered microbiota, enhanced mucosal permeability, infiltration and activation of eosinophils and mast cells, and increased acid exposure have been suggested to be implicated in the pathogenesis of FD. ${ }^{5,12}$ Further, gastric dysbiosis, Helicobacter pylori infection, and atrophic gastritis may also be involved in the pathogenesis. ${ }^{5,12}$ Interactions between pathophysiologic mechanisms or pathogenetic factors under novel concepts are complex, and prediction of underlying mechanisms simply by the symptom pattern or symptombased subtypes seems to be more difficult than before.
Optimal treatment strategy for FD should be based on a detailed understanding of the abnormalities involved in the genesis of dyspeptic symptoms. Symptom-based subtypes based on the Rome criteria are commonly used to select therapeutic agents. However, it is unclear yet whether those subtypes are useful for targeted therapeutic approaches, particularly when considering therapeutic agents targeting novel mechanisms. The aim of this review is to evaluate the usefulness of symptom-based subtypes of FD based on the Rome criteria for predicting underlying pathophysiologic mechanisms and choosing appropriate therapeutic agents.

\section{Association of Dyspeptic Symptoms With Classic Pathophysiologic Mechanisms}

FD is considered to be a heterogeneous disorder with different pathophysiological mechanisms or pathogenetic factors. Several classic pathophysiologic mechanisms have been suggested to be associated with a certain dyspeptic symptom. The association of delayed gastric emptying with nausea and postprandial fullness was reported. ${ }^{3,4}$ Impaired gastric accommodation to a meal was found to be associated with early satiety. ${ }^{2}$ Hypersensitivity to gastric distension was reported to be frequently related to epigastric pain and belching. ${ }^{1}$ Although the prevalence of impaired gastric accommodation is highest in patients with early satiety as a predominant symptom, such abnormality is also commonly observed in patients with other predominant symptoms including epigastric burning, epigastric pain, or postprandial fullness (Fig. 1). ${ }^{13}$ Similarly, the prevalence of delayed gastric emptying for solids is highest in patients with a predominant symptom of postprandial fullness, but that abnormal mechanism can be associated with patients with other predominant symptoms such as early satiety or epigastric burning (Fig. 1). ${ }^{13}$ Delayed gastric emptying and impaired gastric accom-

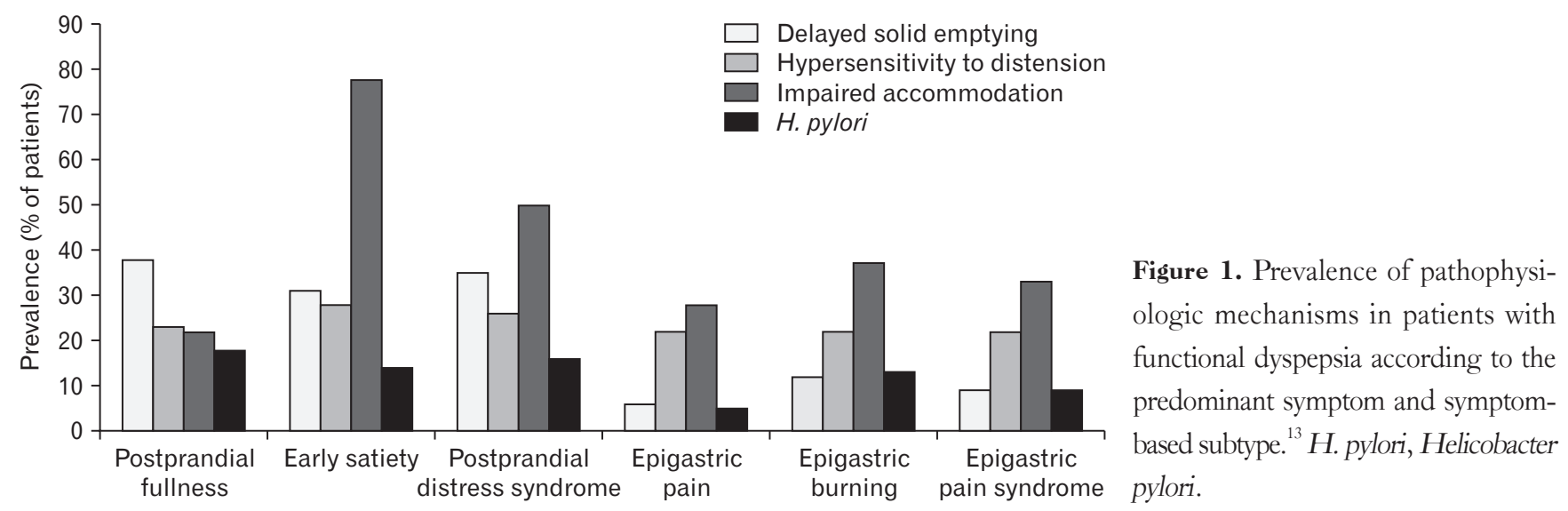


modation may lead to increased gastroesophageal reflux generating burning symptoms. Moreover, some studies failed to show a positive association of delayed gastric emptying with specific FD symptoms. ${ }^{14-16}$ Irrespective of predominant symptoms, hypersensitivity to gastric distension is similarly prevalent in patients with FD (Fig. 1). ${ }^{13}$ Actually, each of classic pathophysiologic mechanisms may be associated with both PDS and EPS (Fig. 1). ${ }^{17}$

In keeping with those findings, a previous study showed that hypersensitivity to gastric distension can induce diverse dyspeptic symptoms, depending on the level of stimuli. For instance, in the induced condition of hypersensitivity to gastric distension in healthy volunteers, sequentially increased distending stimuli to the stomach generated fullness and bloating first, and then nausea, satiety, and epigastric burning, followed by epigastric pain. ${ }^{18}$ Thus, one pathophysiologic mechanism can be associated with multiple dyspeptic symptoms, and a specific dyspeptic symptom may be induced by diverse pathophysiologic mechanisms. Consequently, individual predominant symptoms are likely to have low sensitivities and specificities for predicting underlying pathophysiological mechanisms. Moreover, there may be a considerable overlap of classic pathophysiologic mechanisms that makes it difficult to predict underlying mechanisms by individual dyspeptic symptoms or symptom-based subtypes.

\section{Differences in Underlying Pathophysiologi- cal Mechanisms Between Postprandial Dis- tress Syndrome and Epigastric Pain Syndrome -}

In the Rome III and IV criteria, symptom-based subtypes of FD are recommended rather than FD as a whole: (1) PDS, characterized by the presence of postprandial fullness and/or early satiety, and (2) EPS, characterized by the presence of epigastric pain and/ or epigastric burning. ${ }^{6}$ The rationale for this subdivision is based on the expectation that pathophysiological mechanisms underlying each subtype are different and appropriate therapeutic agents can be selected based on those subtypes. However, a previous study failed to demonstrate any differences between PDS and EPS in the prevalence of gastric hypersensitivity, impaired gastric accommodation, and delayed gastric emptying. ${ }^{17}$ There was no difference in the prevalence of gastric hypersensitivity to distension between subgroups (PDS $30.5 \%$, EPS $21.4 \%$, and overlap 40.6\%). The prevalence of impaired gastric accommodation was also comparable between subgroups (PDS 27.6\%, EPS 42.9\%, and overlap 38.7\%). Likewise, the prevalence of delayed gastric emptying did not significantly differ between subgroups (PDS 23.2\%, EPS 14.9\%, and overlap 23.8\%). ${ }^{17}$ In addition, a substantial overlap between PDS and EPS can decrease the usefulness of those subtypes in predicting underlying pathophysiologic abnormalities. ${ }^{17,19}$

The use of subtypes such as PDS and EPS is further emphasized in the Rome IV as compared to the Rome III. ${ }^{7}$ Compared with Rome III criteria, the overlap between PDS and EPS groups is reported to be reduced by the Rome IV criteria. ${ }^{20,21}$ However, a previous population-based study using the Rome IV criteria also showed a considerable overlap between PDS and EPS (21.0\% in the adult population of the USA, Canada, and the UK). ${ }^{22}$ This overlap hinders prediction of underlying pathophysiologic mechanisms based on symptom-based subtypes. Besides the overlap between PDS and EPS, there may be substantial overlap between underlying pathophysiological mechanisms. ${ }^{17}$ PDS is defined as mealinduced dyspeptic symptoms and more associated with the effect of meal ingestion. Therefore, delayed gastric emptying, impaired gastric accommodation to a meal, and hypersensitivity to distending or chemical stimuli can be associated with meal-related dyspeptic symptoms. Although EPS appears to be less associated with the effect of meal ingestion, visceral hypersensitivity, that is considered to be the main mechanisms of EPS, may produce symptoms postprandially as well as preprandially. Actually, postprandial epigastric pain or burning may occur even in patients with EPS diagnosed by the Rome IV criteria. ${ }^{7}$ Food and dietary factors may also be involved in the pathogenesis of FD. Those factors may be associated with dysbiosis, enhanced mucosal permeability, and low-grade immune activation, particularly in the duodenum. ${ }^{23}$ Those duodenal abnormalities can induce gastric sensorimotor dysfunction and play a role in the generation of both PDS and EPS symptoms. Data on treatment responses to acid suppressants or prokinetic agents in patients with FD using the Rome IV criteria are lacking. Thus, the real effect of the Rome IV definition of FD subgroups on treatment responses needs further investigation.

Pathological gastroesophageal acid reflux was reported to be observed in $18.5 \%$ of FD patients without heartburn. They were characterized by a higher prevalence of epigastric pain. ${ }^{24}$ Similarly, a previous study from China demonstrated high prevalence of pathological gastroesophageal acid reflux in patients with FD. ${ }^{25}$ The prevalence of pathological gastroesophageal acid reflux was the highest (48.9\%) in patients with epigastric burning, 36.6\% in patients with PDS, and $28.7 \%$ in patients with $\mathrm{EPS}^{25}$ The positive rates for PPI tests did not significantly differ between patients with PDS (65.5\%) and EPS (60.6\%) $(P=0.522)$. In that case, the Rome subtyping separated into PDS and EPS could not help in guiding treatment strategy. That may be at least partly attributed to 
the fact that delayed gastric emptying and impaired gastric accommodation to a meal may play a role in increasing gastroesophageal reflux. ${ }^{26}$ Therefore, prediction of underlying abnormalities based on symptom-based subtypes seems to be difficult.

\section{Association of Psychological Factors or Stress With Symptom-based Subtypes of Functional Dyspepsia}

The sensorimotor dysfunction of the gastroduodenal region can be induced by diverse pathogenetic factors. Patients with FD are known to have more psychological problems such as anxiety, depression, and psychological distress than those who do not have $\mathrm{FD}^{27}$ Dyspeptic symptoms are found to be significantly associated with psychosocial factors such as depression and somatization. ${ }^{28}$ Stress is known to be a trigger for dyspeptic symptoms. ${ }^{29}$ Psychological factors or stress may induce abnormal central modulation and enhance visceral sensitivity. ${ }^{30,31}$ It is also found that stress can cause alterations in gastrointestinal motility, enhanced visceral sensitivity, increased epithelial permeability, impaired intestinal barrier function, immune activation, and gut dysbiosis in animal models, ${ }^{32-34}$ and irritable bowel syndrome patients. ${ }^{35}$ Various kinds of psychosocial stress have been shown to induce diverse gastric sensorimotor abnormalities, including delayed gastric emptying, impaired gastric accommodation to a meal, and gastric hypersensitivity to distension in healthy volunteers, suggesting that psychological factors or stress may play a role in the pathogenesis of both PDS and EPS. ${ }^{36,37}$ Therefore, it is unlikely that the involvement of psychological factors or stress is predicted by symptom-based subtypes.

\section{Association of Duodenal Abnormalities With Symptom-based Subtypes of Functional Dyspepsia}

$\mathrm{FD}$ is defined as a disorder characterized by the presence of recurrent or persistent symptoms thought to originate in the gastroduodenal region without any organic, systemic, or metabolic disease that is likely to explain the symptoms. ${ }^{6,7}$ Recently, the duodenum is regarded as the key organ in the generation of dyspepsia symptoms, and it has been proposed that gastric sensorimotor dysfunction may be induced by duodenal abnormalities. ${ }^{38-43}$ Infiltration and activation of eosinophils and mast cells have been identified in the duodenum of patients with $\mathrm{FD}$, and suggested to play a key role in the pathogenesis of FD. ${ }^{41-43}$ Infiltration and activation of eosinophils and mast cells in the duodenum lead to low-grade inflammation and increased mucosal permeability. Those duodenal abnormalities can induce submucous neural changes, neuronal hyperexcitability, and sensitization of the afferent nerve, which triggers duodenogastric reflexes, impairs gastric accommodation, and enhances gastroduodenal sensitivity. ${ }^{43-46}$ Thus, duodenal abnormalities found in a subset of patients FD can be theoretically associated with both PDS and EPS symptoms. Duodenal dysbiosis, food, and dietary factors are also suggested to play a role in inducing duodenal abnormalities such as enhanced mucosal permeability and low-grade immune activation. However, their role in the pathogenesis of FD needs to be further investigated.

Abnormally increased duodenal acid exposure is observed in a subset of patients with $\mathrm{FD}^{47,48}$ Like low-grade immune activation and inflammation of the duodenum, increased duodenal acid exposure can induce gastric sensorimotor dysfunction, probably through triggering duodeno-gastric reflexes, impairing gastric accommodation, and enhancing gastroduodenal sensitivity. ${ }^{40,49,50}$ Therefore, this abnormality leads to pathophysiologic mechanisms generating both PDS and EPS symptoms. Taken together, it appears to be difficult to predict the presence of duodenal abnormalities by symptombased subtypes of FD.

\section{Association of Altered Gut Microbiota With Symptom-based Subtypes of Functional Dyspepsia}

The importance of gut microbiota in gastrointestinal physiology has been well described, and they are believed to be associated with pathophysiology in various diseases. ${ }^{51,52}$ The mechanistic implications of gut microbiome in the pathophysiology of functional gastrointestinal disorders have also been suggested..$^{53}$ Gut microbiome is involved in modulating physiological processes such as immune response, motility, secretion, epithelial barrier integrity, and braingut communication. ${ }^{54}$ Animal studies have shown that gut dysbiosis induces visceral hypersensitivity. ${ }^{55,56}$ Induction of epithelial opioid and cannabinoid receptors, regulation of central and peripheral neuronal pathways, antinociceptive effects through inhibition of transient receptor potential cation channel subfamily $\mathrm{V}$ member 1 , and the effect of microbial metabolites on sensation are suggested as the plausible mechanism. ${ }^{57-62}$ However, the exact mechanisms by which gut microbiota affects visceral sensitivity are not clearly explored in human beings.

It has been shown that intestinal dysbiosis is associated with irritable bowel syndrome. ${ }^{63}$ Similarly, altered gastric microbiota was recently demonstrated in patients with $\mathrm{FD}^{64,65}$ Initially, dysbiosis in 
the gastric fluid of patients with FD was reported. The abundance of genus Prevotella was found to be higher in the gastric fluid of patients with FD than in healthy controls, and inversely correlated with the severity of PDS symptoms. ${ }^{64}$ In another gastric fluid study, gastric microbiota of the FD group was characterized by increased Bacteroidetes to Proteobacteria ratio and total absence of Acidobacteria. ${ }^{65}$ In mucosa-associated microbiota studies, Firmicutes at the phylum level and Streptococcus at the genus level were reported to be increased in patients with FD compared to healthy controls in the stomach and duodenum. ${ }^{66}$ It has been shown that the relative abundance of Streptococcus at the genus level and OTU 90 (the most prevalent sequence of Streptococcus infantis) at the species level are positively correlated with PDS and EPS symptom scores. ${ }^{67}$ Zhong et al. ${ }^{68}$ assessed duodenal mucosal microbiota, and revealed that the relative abundance of Prevotella, Veillonella and Actinomyces was significantly decreased in the FD group.

It cannot be completely excluded that delayed gastric emptying, the use of PPIs, and dietary changes due to dyspepsia may affect microbiota composition in the stomach and duodenum of patients with FD. Although current data cannot explain a direct causative process in $\mathrm{FD}$, dysbiosis is likely to be associated with symptom generation or exacerbation in a subset of patients with FD. Microbial products or metabolites might be involved in the regulation of gastrointestinal motility. ${ }^{69-71}$ On the other hand, duodenal dysbiosis is suggested to play a role in altering mucosal permeability. ${ }^{72}$ Although gastroduodenal dysbiosis may be associated with the generation of both PDS and EPS symptoms, its mechanistic role in FD needs further investigation.

\section{Association of Helicobacter pylori Infection With Symptom-based Subtypes of Function- al Dyspepsia}

The association of $H$. pylori with the development of peptic ulcer disease and gastric cancer has been clearly demonstrated. Chronic inflammation in the gastric mucosa induced by $H$. pylori infection is believed to alter the sensorimotor and secretory function of the stomach. ${ }^{73,74}$ It was found that $H$. pylori infected subjects had significantly lower bacterial diversity and richness compared to those non-infected. ${ }^{75}$ Although this concept has not been clearly established, several consensus or guidelines on dyspepsia or FD recommend $H$. pylori test and treat for the exclusion of $H$. pyloriassociated dyspepsia. ${ }^{8-10,76}$ Particularly, long-term favorable benefits for dyspeptic symptoms after eradication of $H$. pylori can be anticipated in a subset of $H$. pylori infected patients with FD. ${ }^{77,78}$ Such benefits are observed only in a minority of cases (the estimated number needed to treat; 14-15), ${ }^{78,79}$ that can be diagnosed as $H$. pylori-associated dyspepsia. ${ }^{80} \mathrm{H}$. pylori infection is usually asymptomatic, and appears to cause dyspeptic symptoms in a minority of $H$. pylori infected subjects. Therefore, it is necessary to determine whether $H$. pylori infection is a cause or not for dyspeptic symptoms in $H$. pylori infected patients, which requires long-term observation over 6 months. ${ }^{80}$ The relationship of $H$. pylori infection with chronically recurrent dyspeptic symptoms is still a controversial issue. Thus, reduction of the risk of future peptic ulcer disease and gastric cancer is emphasized as the additive rationale behind $H$. pylori test and treat in dyspeptic patients.

Although some epidemiological studies show association of $H$. pylori infection with chronically recurrent dyspeptic symptoms, ${ }^{81} \mathrm{H}$. pylori infection is considered to be less important for dyspepsia than other risk factors including aspirin/NSAIDs use, unemployment, and heavy smoking. ${ }^{82,83}$ Although the prevalence of $H$. pylori infection varies from $20 \%$ to $90 \%$, depending on conditions of development and hygiene, ${ }^{83}$ the prevalence of FD does not seem to be well correlated with that of $H$. pylori infection (Fig. 2 and Table). ${ }^{84-92}$ Likewise, in a Korean nationwide, multicenter study regarding the prevalence of $\mathrm{FD}$ in patients undergoing health check-ups, positive serology for $H$. pylori infection were not associated with the prevalence of FD. ${ }^{93}$ Furthermore, a recent meta-analysis of randomized controlled trials from Asia revealed that the effect of $H$. pylori eradication on dyspeptic symptoms in patients with FD was not

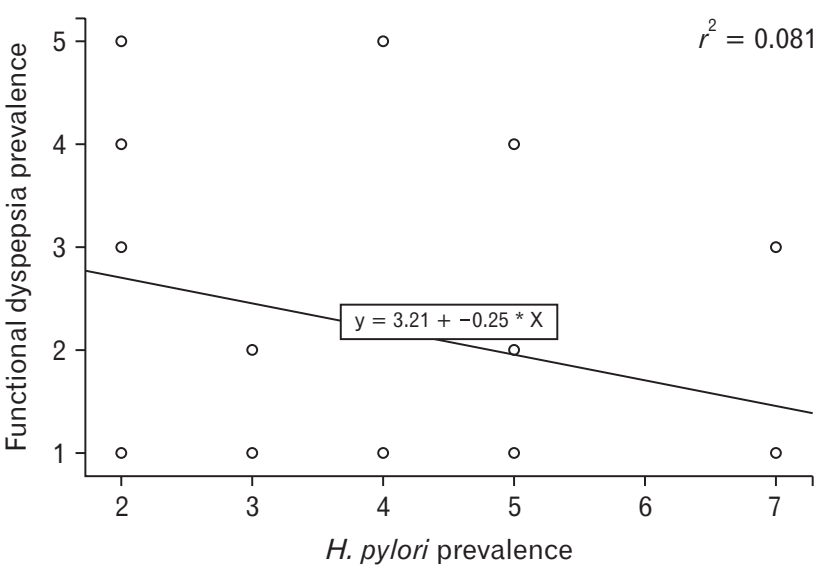

Figure 2. Correlation between prevalence of Helicobacter pylori $(H$. pylori) infection (1, 10.0-19.9\%; 2, 20.0-29.9\%; 3, 30.0-39.9\%; 4, $40.0-49.9 \%$; 5, 50.0-59.9\%; 6, 60.0-69.9\%; 7, 70.0\% or higher) and that of functional dyspepsia $(1,0.0-9.9 \% ; 2,10.0-14.9 \% ; 3$, $15.0-19.9 \%$; 4, 20.0-24.9\%; 5, 25.0-29.9\%). ${ }^{84-92}$ 
Table. Comparison of Prevalence Between Helicobacter pylori Infection and Functional Dyspepsia

\begin{tabular}{lcc}
\hline \multicolumn{1}{c}{ Country } & H. pylori infection ${ }^{\mathrm{a}}$ & Functional dyspepsia $^{\mathrm{b}}$ \\
\hline USA & 3 & 2 \\
Canada & 3 & 1 \\
Mexico & 5 & 1 \\
Brazil & 7 & 3 \\
Argentina & 4 & 5 \\
United Kingdom & 3 & 1 \\
France & 4 & 1 \\
Sweden & 2 & 3 \\
Finland & 5 & 1 \\
Greece & 5 & 4 \\
Turkey & 7 & 1 \\
China & 5 & 2 \\
South Korea & 5 & 1 \\
Malaysia & 2 & 3 \\
Australia & 2 & 4 \\
New Zealand & 2 & 5 \\
Italy & 5 & 2 \\
Denmark & 2 & 1 \\
Japan & 5 & 1 \\
\hline
\end{tabular}

${ }^{a}$ Prevalence of Helicobacter pylori $(H$. pylori) infection in the population (1, $10.0-19.9 \%$; 2, 20.0-29.9\%; 3, 30.0-39.9\%; 4, 40.0-49.9\%; 5, 50.0-59.9\%; 6, $60.0-69.9 \% ; 7,70.0 \%$ or higher $)^{8+92}$

${ }^{\mathrm{b}}$ Prevalence of functional dyspepsia in the population $(1,0.0-9.9 \% ; 2,10.0-$ $14.9 \% ; 3,15.0-19.9 \% ; 4,20.0-24.9 \% ; 5,25.0-29.9 \%){ }^{84-92}$

significant. ${ }^{94}$ Improvement in symptoms after successful eradication is observed in a minority of dyspeptic patients infected with $H$. pylori. Taken together, $H$. pylori infection is more likely to be a minor cause in FD rather than a major one. Dyspeptic patients infected with $H$. pylori have similar clinical characteristics to non-infected dyspeptic patients. ${ }^{95}$ A previous study showed that epigastric pain or burning and postprandial fullness are more intense in dyspeptic patients infected with $H$. pylori than in non-infected dyspeptic patients. $^{96}$

Gastric emptying was reported to be delayed in patients with atrophic gastritis and hypochlorhydria, ${ }^{97}$ suggesting that progression of atrophic gastritis to the proximal stomach by long-lasting $H$. pylori infection may lead to delayed gastric emptying. Actually, there is a previous study demonstrating that gastric emptying improved significantly in dyspeptic patients after successful $H$. pylori eradication, whose dyspeptic symptoms disappeared. ${ }^{98}$ On the contrary, there are data showing the negative association between gastric emptying rate and $H$. pylori status. ${ }^{99,100}$ Atrophic gastritis that progresses to the gastric corpus may result in gastric hypochlorhydria. ${ }^{101}$ A previous study from Japan revealed that dysmotility-related symptom scores were significantly higher in dyspeptic subjects with gastric hypochlorhydria compared with the non-hypochlorhydria group. ${ }^{102}$ Hypochlorhydria-related abnormalities in digestion, absorption, and motility may be responsible for this observation. The association of reduced accommodation with $H$. pylori gastritis was reported. ${ }^{103}$ Similarly, inflammatory changes associated with $H$. pylori infection are also suggested to influence proximal gastric motor function. ${ }^{104}$ Recently, it was found that PDS-like symptoms are associated with atrophic gastritis that progresses to the corpus, and EPS-like symptoms with atrophic gastritis localized to the antrum. ${ }^{105}$ This finding indicates that $H$. pylori-induced chronic atrophic gastritis may be involved in the generation of both EPS and PDS symptoms, probably depending on the extent of atrophic gastritis. Actually, there is a previous report that EPS-like symptoms such as epigastric pain and burning are correlated with the degree of inflammation in patients infected with $H$. pylori. ${ }^{106}$

Dyspepsia with $H$. pylori infection and $H$. pylori-associated dyspepsia are not the same, because $H$. pylori-associated dyspepsia can be diagnosed when dyspeptic symptoms are improved after eradication of $H$. pylori. This improvement after successful eradication is observed only in a small portion of dyspeptic patients infected with $H$. pylori. Although long-lasting $H$. pylori infection evokes chronic inflammatory changes in the stomach and it may affect gastric functions, many patients with $H$. pylori infection do not have any symptoms. Therefore, although $H$. pylori infection can contribute to the generation of EPS or PDS symptoms, it is difficult to determine whether $H$. pylori infection is a cause for symptoms in dyspeptic patients infected with $H$. pylori. That is at least partly attributed to the fact that FD is a multifactorial disease. Symptombased subtypes do not seem to be useful for predicting the pathogenetic role of $H$. pylori infection in dyspeptic patients.

\section{The Association of Symptom-based Sub- types With Pathophysiologic Mechanisms or Therapeutic Agents}

It is ideal to choose appropriate therapeutic agents for FD based on underlying pathophysiologic mechanisms. However, many patients with FD may be associated with multiple pathophysiologic mechanisms, who are less likely to respond to an agent targeting a single mechanism. Furthermore, each dyspeptic symptom is not specific for a particular pathophysiologic mechanism or pathogenetic factor. Each pathogenetic factor may influence the overall function of the gastroduodenal region, and lead to diverse sensorimotor dysfunctions, that may be associated with multiple 
dyspeptic symptoms including both PDS and EPS symptoms. Figure 3 depicts the relationship between symptom-based subtypes of FD and pathophysiologic mechanisms. The presence of a single functional abnormality such as delayed gastric emptying or impaired gastric accommodation to a meal may be associated with one subtype such as PDS or a single dyspeptic symptom. This may explain clinical data of Acotiamide, a prokinetic agent with a feature of fundic relaxants, showing that meal-related PDS symptoms, unlike EPS symptoms, have more prominent therapeutic gains compared to the placebo group. ${ }^{107,108}$ However, in the real world situation, multiple functional abnormalities are more likely to be involved in the generation of dyspeptic symptoms rather than a single functional abnormality. Actually, gastric hypersensitivity, delayed gastric emptying, and impaired gastric accommodation may commonly overlap. ${ }^{17}$ Therefore, in many cases, symptom-based subtypes such as PDS and EPS do not accurately reflect underlying pathophysiologic abnormalities. It is presumed that patients with EPS are more likely to improve with a PPI and those with PDS are more likely to respond to a prokinetic agent. ${ }^{9-11}$ This assumption may be applied in a subset of patients with a functional abnormality related to the action mechanism of the agent. However, some studies have shown that therapeutic responses to a PPI or a prokinetic agent do not differ in the group of EPS or PDS, respectively. ${ }^{109-111}$ In general, a PPI is not expected to show benefit in patients with dysmotility-like dyspepsia. However, a previous study from Japan demonstrated that PPI monotherapy was significantly more effective in improving dysmotility-like symptoms than prokinetics, ${ }^{109}$ suggesting that symptom-based subtypes of FD may not be useful for choosing

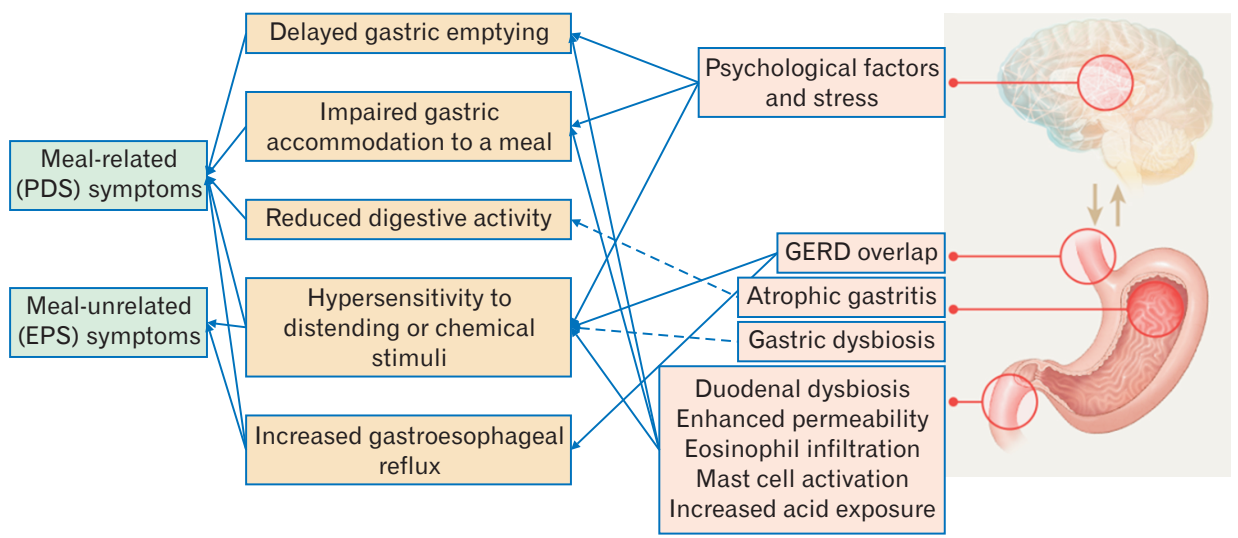

Figure 3. Relationship between symptombased subtypes and plausible pathophysiologic mechanisms in functional dyspepsia (dotted lines indicate inadequate evidence requiring further investigation). PDS, postprandial distress syndrome; EPS, epigastric pain syndrome; GERD, gastroesophageal reflux disease.

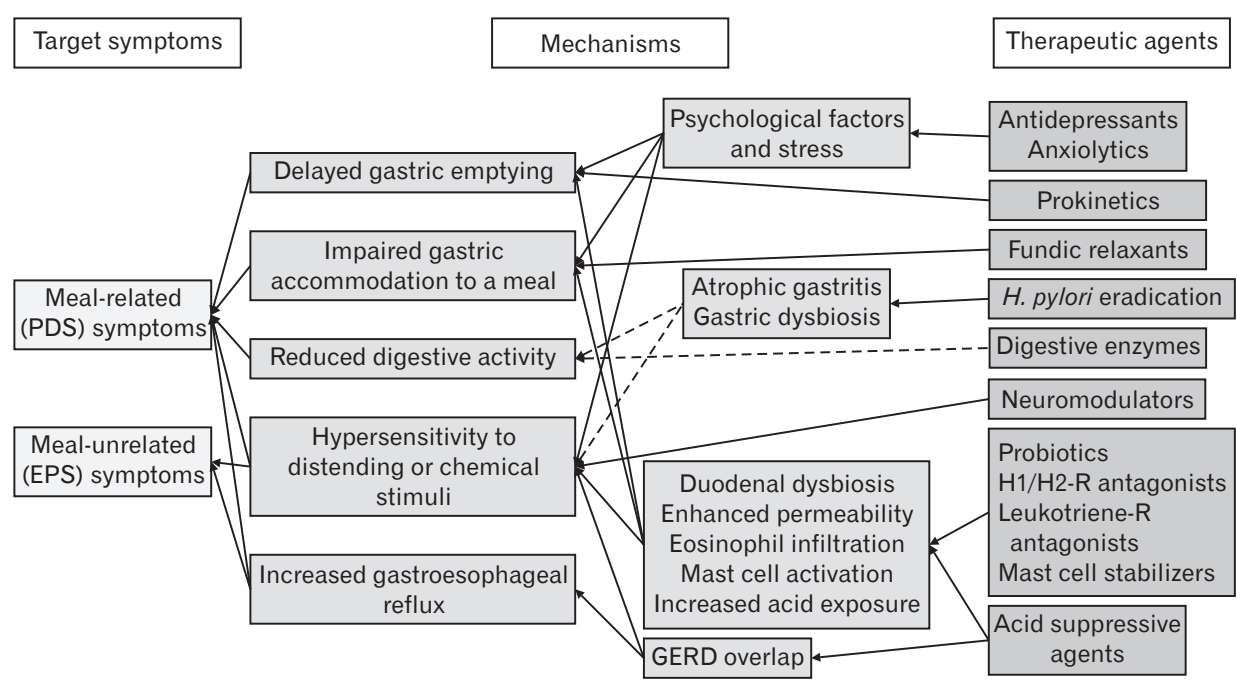

Figure 4. Relationship between symptom-based subtypes and plausible therapeutic agents in functional dyspepsia (dotted lines indicate inadequate evidence requiring further investigation). PDS, postprandial distress syndrome; EPS, epigastric pain syndrome; GERD, gastroesophageal reflux disease; H. pylori, Helicobacter pylori; H1/H2-R, histamine H1/H2 receptor; Leukotriene-R, Leukotriene receptor. 
effective therapeutic agents. The previous data are mostly based on the Rome III criteria, and clinical trial data using the Rome IV subgroup definition are lacking. However, when considering the complex interactions between pathophysiologic mechanisms and pathogenetic factors, and their common overlap, prediction of underlying pathophysiologic abnormalities simply by symptom-based subtypes does not seem to be accurate. Particularly, novel concepts on the pathophysiology of FD makes it more difficult and complex than before.

The addition of objective parameters or subclassification reflecting physiologic or pathologic tests seems to be necessary for the targeted therapeutic approaches, particularly when therapeutic agents targeting novel mechanisms are available. The pathophysiologic mechanisms, that can be therapeutic targets at present, include increased acid exposure of the duodenum or esophagus, reduced gastric or duodenal motility, impaired gastric accommodation, atrophic gastritis with $H$. pylori, low-grade mucosal inflammation or enhanced mucosal permeability of the duodenum, altered microbiota, psychological factors or stress, and enhanced sensitivity of the stomach or duodenum. Although some candidate agents need further investigation to show their beneficial effects on dyspeptic symptoms, therapeutic agents targeting classic and novel pathophysiologic mechanisms include prokinetics, fundic relaxants, acid suppressive agents, neuromodulators, antidepressants, anxiolytics, digestive enzymes, histamine $\mathrm{H} 1 / \mathrm{H} 2$ receptor antagonists, leukotriene receptor antagonists, mast cell stabilizers, and probiotics (Fig. 4). Easily applicable tests in real clinical situations are required for the targeted therapeutic approaches. For example, simplified questionnaires for assessing psychological factors and stress, noninvasive tests for measuring gastric emptying, accommodation, and sensitivity, histologic markers of eosinophil or mast cell activation in the duodenum, $\mathrm{pH}$ monitoring or impedance measurement of the duodenum, or endoscopic grade of atrophic gastritis with $H$. pylori tests may be necessary. Because those tests are not commonly performed at present in real clinical situations, combined therapy of drugs with different action mechanisms or the use of multi-target therapeutic agents may be more practically effective rather than monotherapy or the use of a single-target agent.

\section{Conclusions}

Although several classic pathophysiologic mechanisms are suggested to be associated with individual dyspeptic symptoms, symptom-based subtypes of FD are not specific for a certain pathogenetic factor or pathophysiologic mechanism, and may be frequently associated with multiple pathophysiologic abnormalities. Novel concepts on the pathophysiology of FD show complex interactions between pathophysiologic mechanisms and pathogenetic factors, and prediction of underlying mechanisms of individual patients simply by the symptom pattern or symptom-based subtypes may not be accurate in a considerable proportion of cases. Therefore, subtyping by the Rome criteria appears to have limited value to guide therapeutic strategy, suggesting that the addition of objective parameters or subclassification reflecting physiologic or pathologic tests may be necessary for the targeted therapeutic approaches, particularly when therapeutic agents targeting novel mechanisms are available.

\section{Financial support: None.}

\section{Conflicts of interest: None.}

Author contributions: Kwang Jae Lee wrote the manuscript and approved the last version.

\section{References}

1. Tack J, Caenepeel P, Fischler B, Piessevaux H, Janssens J. Symptoms associated with hypersensitivity to gastric distention in functional dyspepsia. Gastroenterology 2001;121:526-535.

2. Tack J, Piessevaux H, Coulie B, Caenepeel P, Janssens J. Role of impaired gastric accommodation to a meal in functional dyspepsia. Gastroenterology 1998;115:1346-1352.

3. Stanghellini V, Tosetti C, Paternico A, et al. Risk indicators of delayed gastric emptying of solids in patients with functional dyspepsia. Gastroenterology 1996;110:1036-1042.

4. Sarnelli G, Caenepeel P, Geypens B, Janssens J, Tack J. Symptoms associated with impaired gastric emptying of solids and liquids in functional dyspepsia. Am J Gastroenterol 2003;98:783-788.

5. Shindo T, Futagami S, Hiratsuka T, et al. Comparison of gastric emptying and plasma ghrelin levels in patients with functional dyspepsia and non-erosive reflux disease. Digestion 2009;79:65-72.

6. Tack J, Talley NJ, Camilleri M, et al. Functional gastroduodenal disorders. Gastroenterology 2006;130:1466-1479.

7. Stanghellini V, Chan FK, Hasler WL, et al. Gastroduodenal disorders. Gastroenterology 2016;150:1380-1392.

8. Talley NJ. Functional dyspepsia: new insights into pathogenesis and therapy. Korean J Intern Med 2016;31:444-456.

9. Miwa H, Kusano M, Arisawa T, et al. Evidence-based clinical practice guidelines for functional dyspepsia. J Gastroenterol 2015;50:125-139.

10. Enck P, Azpiroz F, Boeckxstaens G, et al. Functional dyspepsia. Nat Rev Dis Primers 2017;3:17081.

11. Geeraerts B, Tack J. Functional dyspepsia: past, present, and future. J Gastroenterol 2008;43:251-255.

12. Wauters L, Talley NJ, Walker MM, Tack J, Vanuytsel T. Novel concepts in the pathophysiology and treatment of functional dyspepsia. Gut 
2020;69:591-600

13. Karamanolis G, Caenepeel P, Arts J, Tack J. Association of the predominant symptom with clinical characteristics and pathophysiological mechanisms in functional dyspepsia. Gastroenterology 2006;130:296303.

14. Talley NJ, Verlinden M, Jones M. Can symptoms discriminate among those with delayed or normal gastric emptying in dysmotility-like dyspepsia? Am J Gastroenterol 2001;96:1422-1428.

15. Stanghellini V, Tack J. Gastroparesis: separate entity or just a part of dyspepsia? Gut 2014;63:1972-1978.

16. Asano H, Tomita T, Nakamura K, et al. Prevalence of gastric motility disorders in patients with functional dyspepsia. J Neurogastroenterol Motil 2017;23:392-399.

17. Vanheel H, Carbone F, Valvekens L, et al. Pathophysiological abnormalities in functional dyspepsia subgroups according to the Rome III criteria. Am J Gastroenterol 2017;112:132-140.

18. Lee KJ, Kim JH, Cho SW. Dyspeptic symptoms associated with hypersensitivity to gastric distension induced by duodenal acidification. J Gastroenterol Hepatol 2006;21:515-520.

19. Matsuzaki J, Suzuki H, Asakura K, et al. Classification of functional dyspepsia based on concomitant bowel symptoms. Neurogastroenterol Motil 2012;24:325-e164.

20. Van den Houte K, Carbone F, Goelen N, et al. Effects of Rome IV definitions of functional dyspepsia subgroups in secondary care. Clin Gastroenterol Hepatol 2020:S1542-3565(20)30906-X.

21. Carbone F, Vanuytsel T, Tack J. Analysis of postprandial symptom patterns in subgroups of patients with Rome III or Rome IV functional dyspepsia. Clin Gastroenterol Hepatol 2020;18:838-846, e3.

22. Aziz I, Palsson OS, Törnblom H, Sperber AD, Whitehead WE, Simrén M. Epidemiology, clinical characteristics, and associations for symptom-based Rome IV functional dyspepsia in adults in the USA, Canada, and the UK: a cross-sectional population-based study. Lancet Gastroenterol Hepatol 2018;3:252-262.

23. Wauters L, Talley NJ, Walker MM, Tack J, Vanuytsel T. Novel concepts in the pathophysiology and treatment of functional dyspepsia. Gut 2020;69:591-600.

24. Tack J, Caenepeel P, Arts J, Lee KJ, Sifrim D, Janssens J. Prevalence of acid reflux in functional dyspepsia and its association with symptom profile. Gut 2005;54:1370-1376.

25. Xiao YL, Peng S, Tao J, et al. Prevalence and symptom pattern of pathologic esophageal acid reflux in patients with functional dyspepsia based on the Rome III criteria. Am J Gastroenterol 2010;105:2626-2631.

26. Pauwels A, Altan E, Tack J. The gastric accommodation response to meal intake determines the occurrence of transient lower esophageal sphincter relaxations and reflux events in patients with gastro-esophageal reflux disease. Neurogastroenterol Motil 2014;26:581-588.

27. Adibi P, Keshteli AH, Daghaghzadeh H, Roohafza H, Pournaghshband N, Afshar H. Association of anxiety, depression, and psychological distress in people with and without functional dyspepsia. Adv Biomed Res 2016;5:195.

28. Van Oudenhove L, Vandenberghe J, Geeraerts B, et al. Determinants of symptoms in functional dyspepsia: gastric sensorimotor function, psy- chosocial factors or somatisation? Gut 2008;57:1666-1673.

29. Piessevaux H, De Winter B, Louis E, et al. Dyspeptic symptoms in the general population: a factor and cluster analysis of symptom groupings. Neurogastroenterol Motil 2009;21:378-388.

30. Lee IS, Wang H, Chae Y, Preissl H, Enck P. Functional neuroimaging studies in functional dyspepsia patients: a systematic review. Neurogastroenterol Motil 2016;28:793-805.

31. Van Oudenhove L, Aziz Q. The role of psychosocial factors and psychiatric disorders in functional dyspepsia. Nat Rev Gastroenterol Hepatol 2013;10:158-167.

32. Zheng G, Wu SP, Hu Y, Smith DE, Wiley JW, Hong S. Corticosterone mediates stress-related increased intestinal permeability in a regionspecific manner. Neurogastroenterol Motil 2013;25:e127-e139.

33. De Palma G, Blennerhassett P, Lu J, et al. Microbiota and host determinants of behavioural phenotype in maternally separated mice. Nat Commun 2015;6:7735.

34. Xu D, Gao J, Gillilland M 3rd, et al. Rifaximin alters intestinal bacteria and prevents stress-induced gut inflammation and visceral hyperalgesia in rats. Gastroenterology 2014;146:4848-496, e4.

35. Dunlop SP, Hebden J, Campbell E, et al. Abnormal intestinal permeability in subgroups of diarrhea-predominant irritable bowel syndromes. Am J Gastroenterol 2006;101:1288-1294.

36. Geeraerts B, Vandenberghe J, van Oudenhove L, et al. Influence of experimentally induced anxiety on gastric sensorimotor function in humans. Gastroenterology 2005;129:1437-1444.

37. Lee HS, An YS, Kang JK, Yoo JH, Lee KJ. Effect of acute auditory stress on gastric motor responses to a meal in healthy volunteers. J Gastroenterol Hepatol 2013;28:1699-1704.

38. Lee KJ, Tack J. Duodenal implications in the pathophysiology of functional dyspepsia. J Neurogastroenterol Motil 2010;16:251-257.

39. Jung HK, Talley NJ. Role of the duodenum in the pathogenesis of functional dyspepsia: a paradigm shift. J Neurogastroenterol Motil 2018;24:345-354.

40. Lee KJ, Vos R, Janssens J, Tack J. Influence of duodenal acidification on the sensorimotor function of the proximal stomach in humans. Am J Physiol Gastrointest Liver Physiol 2004;286:G278-G284.

41. Walker MM, Talley NJ. The role of duodenal inflammation in functional dyspepsia. J Clin Gastroenterol 2017;51:12-18.

42. Du L, Shen J, Kim JJ, Yu Y, Ma L, Dai N. Increased duodenal eosinophil degranulation in patients with functional dyspepsia: a prospective study. Sci Rep 2016;6:34305.

43. Vanheel H, Vicario M, Vanuytsel T, et al. Impaired duodenal mucosal integrity and low-grade inflammation in functional dyspepsia. Gut 2014;63:262-271.

44. Walker MM, Talley NJ, Prabhakar M, et al. Duodenal mastocytosis, eosinophilia and intraepithelial lymphocytosis as possible disease markers in the irritable bowel syndrome and functional dyspepsia. Aliment Pharmacol Ther 2009;29:765-773.

45. Cirillo C, Bessissow T, Desmet AS, Vanheel H, Tack J, Vanden Berghe P. Evidence for neuronal and structural changes in submucous ganglia of patients with functional dyspepsia. Am J Gastroenterol 2015;110:12051215. 
46. Talley NJ, Walker MM, Aro P, et al. Non-ulcer dyspepsia and duodenal eosinophilia: an adult endoscopic population-based case-control study. Clin Gastroenterol Hepatol 2007;5:1175-1183.

47. Lee KJ, Demarchi B, Demedts I, Sifrim D, Raeymaekers P, Tack J. A pilot study on duodenal acid exposure and its relationship to symptoms in functional dyspepsia with prominent nausea. Am J Gastroenterol 2004;99:1765-1773.

48. Bratten J, Jones MP. Prolonged recording of duodenal acid exposure in patients with functional dyspepsia and controls using a radiotelemetry pH monitoring system. J Clin Gastroenterol 2009;43:527-533.

49. Lee KJ, Kim JH, Cho SW. Dyspeptic symptoms associated with hypersensitivity to gastric distension induced by duodenal acidification. J Gastroenterol Hepatol 2006;21:515-520.

50. Lin HC, Doty JE, Reedy TJ, Meyer JH. Inhibition of gastric emptying by acids depends on $\mathrm{pH}$, titratable acidity, and length of intestine exposed to acid. Am J Physiol 1990;259(6 Pt 1):G1025-G1030.

51. Reigstad CS, Kashyap PC. Beyond phylotyping: understanding the impact of gut microbiota on host biology. Neurogastroenterol Motil 2013;25:358-372.

52. Lynch SV, Pedersen O. The human intestinal microbiome in health and disease. N Engl J Med 2016;375:2369-2379.

53. Barbara G, Feinle-Bisset C, Ghoshal UC, et al. The intestinal microenvironment and functional gastrointestinal disorders. Gastroenterology 2016;150:1305-1318, e8.

54. Shin A, Preidis GA, Shulman R, Kashyap PC. The gut microbiome in adult and pediatric functional gastrointestinal disorders. Clin Gastroenterol Hepatol 2019;17:256-274.

55. Riba A, Olier M, Lacroix-Lamandé S, et al. Paneth cell defects induce microbiota dysbiosis in mice and promote visceral hypersensitivity. Gastroenterology 2017;153:1594-1606, e2.

56. O'Mahony SM, Felice VD, Nally K, et al. Disturbance of the gut microbiota in early-life selectively affects visceral pain in adulthood without impacting cognitive or anxiety-related behaviors in male rats. Neuroscience 2014;277:885-901.

57. Rousseaux C, Thuru X, Gelot A, et al. Lactobacillus acidophilus modulates intestinal pain and induces opioid and cannabinoid receptors. Nat Med 2007;13:35-37.

58. Ait-Belgnaoui A, Eutamene H, Houdeau E, Bueno L, Fioramonti $\mathrm{J}$, Theodorou V. Lactobacillus farciminis treatment attenuates stressinduced overexpression of Fos protein in spinal and supraspinal sites after colorectal distension in rats. Neurogastroenterol Motil 2009;21:567573, e18-e19.

59. Kunze WA, Mao YK, Wang B, et al. Lactobacillus reuteri enhances excitability of colonic $\mathrm{AH}$ neurons by inhibiting calcium-dependent potassium channel opening. J Cell Mol Med 2009;13(8B):2261-2270.

60. Perez-Burgos A, Wang L, McVey Neufeld KA, et al. The TRPV1 channel in rodents is a major target for antinociceptive effect of the probiotic Lactobacillus reuteri DSM 17938. J Physiol 2015;593:3943-3957.

61. Pokusaeva K, Johnson C, Luk B, et al. GABA-producing Bifidobacterium dentium modulates visceral sensitivity in the intestine. Neurogastroenterol Motil 2017;29:e12904.

62. Bourdu S, Dapoigny M, Chapuy E, et al. Rectal instillation of butyrate provides a novel clinically relevant model of noninflammatory colonic hypersensitivity in rats. Gastroenterology 2005;128:1996-2008.

63. Pimentel M, Lembo A. Microbiome and its role in irritable bowel syndrome. Dig Dis Sci 2020;65:829-839.

64. Nakae H, Tsuda A, Matsuoka T, Mine T, Koga Y. Gastric microbiota in the functional dyspepsia patients treated with probiotic yogurt. BMJ Open Gastroenterol 2016;3:e000109.

65. Igarashi M, Nakae H, Matsuoka T, et al. Alteration in the gastric microbiota and its restoration by probiotics in patients with functional dyspepsia. BMJ Open Gastroenterol 2017;4:e000144.

66. Paroni Sterbini F, Palladini A, Masucci L, et al. Effects of proton pump inhibitors on the gastric mucosa-associated microbiota in dyspeptic patients. Appl Environ Microbiol 2016;82:6633-6644.

67. Fukui A, Takagi T, Naito Y, et al. Higher levels of streptococcus in upper gastrointestinal mucosa associated with symptoms in patients with functional dyspepsia. Digestion 2020;101:38-45.

68. Zhong L, Shanahan ER, Raj A, et al. Dyspepsia and the microbiome: time to focus on the small intestine. Gut 2017;66:1168-1169.

69. Anitha M, Vijay-Kumar M, Sitaraman SV, Gewirtz AT, Srinivasan S. Gut microbial products regulate murine gastrointestinal motility via Tolllike receptor 4 signaling. Gastroenterology 2012;143:1006-1016, e4.

70. Jimenez M, Gil V, Martinez-Cutillas M, Mañé N, Gallego D. Hydrogen sulphide as a signalling molecule regulating physiopathological processes in gastrointestinal motility. Br J Pharmacol 2017;174:2805-2817.

71. Ritz NL, Lin DM, Wilson MR, Barton LL, Lin HC. Sulfate-reducing bacteria slow intestinal transit in a bismuth-reversible fashion in mice. Neurogastroenterol Motil 2017;29:e12907.

72. Raj AS, Shanahan ER, Tran CD, et al. Dysbiosis of the duodenal mucosal microbiota is associated with increased small intestinal permeability in chronic liver disease. Clin Transl Gastroenterol 2019;10:e00068.

73. Zullo A, Hassan C, De Francesco V, et al. Helicobacter pylori and functional dyspepsia: an unsolved issue? World J Gastroenterol 2014;20:8957-8963.

74. Zhang CL, Geng CH, Yang ZW, et al. Changes in patients' symptoms and gastric emptying after Helicobacter pylori treatment. World J Gastroenterol 2016;22:4585-4593.

75. Talley NJ. American gastroenterological association medical position statement: evaluation of dyspepsia. Gastroenterology 2005;129:17531755.

76. Sugano K. Should we still subcategorize Helicobacter pylori-associated dyspepsia as functional disease? J Neurogastroenterol Motil 2011;17:366-371.

77. Xu S, Wan X, Zheng X, et al. Symptom improvement after Helicobacter pylori eradication in patients with functional dyspepsia-a multicenter, randomized, prospective cohort study. Int J Clin Exp Med 2013;6:747-756. eCollection 2013.

78. Moayyedi P, Soo S, Deeks J, et al. Eradication of Helicobacter pylori for non-ulcer dyspepsia. Cochrane Database Syst Rev 2006;CD002096.

79. Armstrong D. Helicobacter pylori infection and dyspepsia. Scand J Gastroenterol Suppl 1996;215:38-47.

80. Sugano K, Tack J, Kuipers EJ, et al. Kyoto global consensus report on Helicobacter pylori gastritis. Gut 2015;64:1353-1367. 
81. Wildner-Christensen M, Hansen JM, De Muckadell OB. Risk factors for dyspepsia in a general population: non-steroidal anti-inflammatory drugs, cigarette smoking and unemployment are more important than Helicobacter pylori infection. Scand J Gastroenterol 2006;41:149-154.

82. Nandurkar S, Talley NJ, Xia H, Mitchell H, Hazel S, Jones M. Dyspepsia in the community is linked to smoking and aspirin use but not to Helicobacter pylori infection. Arch Intern Med 1998;158:1427-1433.

83. Malfertheiner P, Selgard M. Helicobacter infection and current clinical areas of contention. Curr Opin Gastroenterol 2010;26:618-623.

84. Hooi JKY, Lai WY, Ng WK, et al. Global prevalence of Helicobacter pylori infection: systematic review and meta-analysis. Gastroenterology 2017:153:420-429.

85. Ford AC, Marwaha A, Sood R, Moayyedi P. Global prevalence of, and risk factors for uninvestigated dyspepsia: a meta-analysis. Gut 2015;64:1049-1057.

86. Aziz I, Palsson OS, Törnblom H, Sperber AD, Whitehead WE, Simrén M. Epidemiology, clinical characteristics, and associations for symptom-based Rome IV functional dyspepsia in adults in the USA, Canada, and the UK: a cross-sectional population-based study. Lancet Gastroenterol Hepatol 2018;3:252-262.

87. Vargas-Matos I, Ng-Sueng LF, Flores-Arriaga J, et al. [Overlap of irritable bowel syndrome and functional dyspepsia based on Rome III criteria in medical students from a private university in Lima, Peru.] Rev Gastroenterol Peru 2015;35:129-225. [Spanish]

88. Schnabel L, Buscail C, Sabate JM, et al. Association between ultraprocessed food consumption and functional gastrointestinal disorders: results from the French NutriNet-Santé Cohort. Am J Gastroenterol 2018;113:1217-1228.

89. Zagari RM, Law GR, Fuccio L, et al. Epidemiology of functional dyspepsia and subgroups in the Italian general population: an endoscopic study. Gastroenterology 2010;138:1302-1311.

90. Rasmussen S, Jensen TH, Henriksen SL, et al. Overlap of symptoms of gastroesophageal reflux disease, dyspepsia and irritable bowel syndrome in the general population. Scand J Gastroenterol 2015;50:162-169.

91. Oshima T, Miwa H. Epidemiology of functional gastrointestinal disorders in Japan and in the world. J Neurogastroenterol Motil 2015;21:320-329.

92. Lee SY, Lee KJ, Kim SJ, Cho SW. Prevalence and risk factors for overlaps between gastroesophageal reflux disease, dyspepsia, and irritable bowel syndrome: a population-based study. Digestion 2009;79:196-201.

93. Kim SE, Park HK, Kim N, et al. Prevalence and risk factors of functional dyspepsia: a nationwide multicenter prospective study in Korea. J Clin Gastroenterol 2014;48:e12-e18.

94. Kang SJ, Park B, Shin CM. Helicobacter pylori eradication therapy for functional dyspepsia: a meta-analysis by region and $H$. pylori prevalence. J Clin Med 2019;8:1324.

95. Rodríguez-García JL, Carmona-Sánchez R. Functional dyspepsia and dyspepsia associated with Helicobacter pylori infection: do they have different clinical characteristics? Rev Gastroenterol Méx 2016;81:126-133.

96. Tucci A, Corinaldesi R, Stanghellini V, et al. Helicobacter pylori infection and gastric function in patients with chronic idiopathic dyspepsia.
Gastroenterology 1992;103:768-774.

97. Tucci A, Poli L, Biasco G, et al. Helicobacter pylori infection and gastric function in patients with fundic atrophic gastritis. Dig Dis Sci 2001;46:1573-1583.

98. Murakami K, Fujioka T, Shiota K, et al. Influence of Helicobacter pylori infection and the effects of its eradication on gastric emptying in nonulcerative dyspepsia. Eur J Gastroenterol Hepatol 1995;7(suppl 1):S93S97.

99. Leontiadis GI, Minopoulos GI, Maltezos E, et al. Effects of Helicobacter pylori infection on gastric emptying rate in patients with non-ulcer dyspepsia. World J Gastroenterol 2004;10:1750-1754.

100. Chang CS, Chen GH, Kao CH, Wang Sj, Peng SN, Huang CK. The effect of Helicobacter pylori infection on gastric emptying of digestible and indigestible solids in patients with nonulcer dyspepsia. Am J Gastroenterol 1996;91:474-479.

101. Sipponen P, Kekki M, Seppälä K, Siurala M. The relationships between chronic gastritis and gastric acid secretion. Aliment Pharmacol Ther 1996;10(suppl 1):103-118.

102. Iwai W, Abe Y, Iijima K, et al. Gastric hypochlorhydria is associated with an exacerbation of dyspeptic symptoms in female patients. J Gastroenterol 2013;48:214-221.

103. Saslow SB, Thumshirn M, Camilleri M, et al. Influence of $H$. pylori infection on gastric motor and sensory function in asymptomatic volunteers. Dig Dis Sci 1998;43:258-264.

104. van der Schaar PJ, Straathof JW, Veenendaal RA, Lamers CB, Masclee AA. Does Helicobacter pylori gastritis affect motor function of proximal stomach in dyspeptic patients? Dig Dis Sci 2001;46:1833-1838.

105. Chung SH, Lee KJ, Kim JY, et al. Association of the extent of atrophic gastritis with specific dyspeptic symptoms. J Neurogastroenterol Motil 2015;21:528-536.

106. Czinn SJ, Bertram TA, Murray PD, Yang P. Relationship between gastric inflammatory response and symptoms in patients infected with Helicobacter pylori. Scand J Gastroenterol 1991;26 (suppl 181):33-37.

107. Xiao G, Xie X, Fan J, et al. Efficacy and safety of acotiamide for the treatment of functional dyspepsia: systematic review and meta-analysis. ScientificWorldJournal 2014;2014:541950.

108. Altan E, Masaoka T, Farré R, Tack J. Acotiamide, a novel gastroprokinetic for the treatment of patients with functional dyspepsia: postprandial distress syndrome. Expert Rev Gastroenterol Hepatol 2012;6:533-544.

109. Hsu YC, Liou JM, Yang TH, et al. Proton pump inhibitor versus prokinetic therapy in patients with functional dyspepsia: is therapeutic response predicted by Rome III subgroups? J Gastroenterol 2011;46:183190.

110. Jung HK, Lee KJ, Choi MG, et al. Efficacy of DA-9701 (motilitone) in functional dyspepsia compared to pantoprazole: a multicenter, randomized, double-blind, non-inferiority study. J Neurogastroenterol Motil 2016;22:254-263.

111. Sakaguchi M, Takao M, Ohyama Y, et al. Comparison of PPIs and H2-receptor antagonists plus prokinetics for dysmotility-like dyspepsia. World J Gastroenterol 2012;18:1517-1524. 